\title{
Effect of tibiotarsal joint inflammation on gene expression and cross-sectional area in rat soleus muscle
}

\author{
Carolina Ramírez ${ }^{1,2}$, Thiago L. Russo ${ }^{1}$, Gabriel Delfino', \\ Sabrina M. Peviani ${ }^{1}$, Carolina Alcântara ${ }^{1}$, Tania F. Salvini ${ }^{1}$
}

ABSTRACT | Background: Joint inflammation is a common clinical problem in patients treated by physical therapists. The hypothesis of this study is that joint inflammation induces molecular and structural changes in the soleus muscle, which is composed mainly of slow-twitch muscle fibers. Objective: To study the effect of tibiotarsal joint inflammation on muscle fiber cross-sectional area (CSA), gene expression levels (atrogin-1, MuRF1, MyoD, myostatin, p38MAPK, NFkB, TNF-alpha), and TNF-alpha protein in the soleus muscle. Method: Wistar rats were randomly divided into 3 periods (2, 7 and 15 days) and assigned to 4 groups (control, sham, inflammation, and immobilization). Results: In the inflammation group at 2 days, MuRF1 and p38MAPK expression had increased, and NFkB mRNA levels had decreased. At 7 days, myostatin expression had decreased. At 7 and 15 days, this group had muscle fiber CSA reduction. At 2 days, the immobilization group showed increased atrogin-1, MuRF1, NFkB, MyoD, and p38MAPK expressions and reduced muscle fiber CSA. At 7 and 15 days, myostatin mRNA levels had increased, and the CSA had decreased. The sham group showed increased p38MAPK and myostatin expressions at 2 and 7 days, respectively. No changes occurred in TNF-alpha gene or protein expression. Conclusion: Acute joint inflammation induces gene expression related to the proteolytic pathway without reduction in muscle fiber CSA. Chronic joint inflammation induced muscle atrophy without up-regulation of important genes belonging to the proteolytic pathway. Thus, muscle adaptation may differ according to the stage of joint inflammation, which suggests that the therapeutic modalities used by physical therapists at each stage should also be different.

Keywords: skeletal muscle; joint disease; gene expression; muscle plasticity; physical therapy; rehabilitation.

\section{HOW TO CITE THIS ARTICLE}

Ramírez C, Russo TL, Delfino G, Peviani SM, Alcântara C, Salvini TF. Effect of tibiotarsal joint inflammation on gene expression and cross-sectional area in rat soleus muscle. Braz J Phys Ther. 2013 May-June; 17(3):244-254. http://dx.doi.org/10.1590/ S1413-35552012005000084

\section{Introduction}

Joint inflammation is a musculoskeletal impairment commonly observed in patients treated by physical therapists, and it can have a significant effect on the patients' quality of life. Inflammation is an innate system of cellular and humoral responses following injuries, in which the body removes the injurious stimuli and initiates the healing process ${ }^{1,2}$. In the musculoskeletal system, inflammation plays an active role in the pathophysiology of disparate joint conditions and chronic diseases treated by physical therapists including traumatic joint injuries, such as sprains, fractures, ligament injuries, and contusions ${ }^{2-4}$.

To better understand the acute and chronic inflammatory process, animal models have been used, such as intra-articular injection of carrageenan in rats. Carrageenan is an agent derived from red seaweed that causes inflammation and hyperalgesia when injected into tissues but not when ingested or applied topically ${ }^{5-7}$. Previous studies have shown that an intra-articular injection of carrageenan triggers an acute inflammatory response within the first few days. This response is converted to macrophage-dominated chronic inflammation by the first week, and it lasts through the $8^{\text {th }}$ week ${ }^{6}$.

Studies using carrageenan have focused mainly on the characterization of the inflammatory response in the joint ${ }^{5,6}$, and little attention has been given to the possible effect that the joint inflammation could have on tissues functionally related to the inflamed joint, such as the skeletal muscle. A recent study conducted in our laboratory found that chronic inflammation of the tibiotarsal joint induced changes in the inflammatory molecular pathways related to regulation of mass leading to atrophy in the tibialis 
anterior, a muscle composed mainly of type II fibers ${ }^{7}$. Conversely, there are no studies that analyze the possible effects of intra-articular injection of carrageenan on slow-twitch muscles such as the soleus, an anti-gravity muscle. It is relevant for physical therapists to study this issue in order to understand how the skeletal muscle adapts to joint inflammation and to develop specific treatment strategies accordingly.

The scientific literature has already described the skeletal muscle as a highly plastic tissue that is sensitive to different conditions of disuse, such as immobilization, hindlimb unloading, and denervation $^{8,9}$, and gene expression and protein content regulations are the main events responsible for inducing morphological and functional changes in skeletal muscles. In humans, clinical studies have described joint conditions that are accompanied by inflammation ${ }^{10-12}$ and that have been related to significant muscle changes, such as atrophy.

Muscle atrophy is a highly regulated and ordered process resulting in reduced muscle fiber crosssectional area (CSA), protein content and force ${ }^{8,11}$, increased fatigue and insulin resistance ${ }^{9}$, and the transformation of type I fibers into type II fibers ${ }^{8,9}$. In rats and humans, molecular changes have been detected during muscle atrophy, including up-regulation of two E3 ubiquitin ligases, i.e. MAFbx (also known as atrogin-1) and Muscle Ring Finger-1 (MuRF1) $)^{13-16}$. Muscle fiber CSA reduction is also followed by changes in the regulation of genes related to muscle differentiation and growth $(\mathrm{MyoD})^{17,18}$ mass regulation (myostatin) ${ }^{19}$ and proinflammatory factors, such as $\mathrm{p} 38$ Mitogen-Activated Protein Kinase (p38MAPK), Nuclear Factor kappa B-dependent (NFkB), and Tumour Necrosis Factoralpha (TNF-alpha) ${ }^{20-22}$. According to a previous study, the carrageenan injection increases TNF-alpha ${ }^{23}$, a cytokine able to increase the gene expression of MuRF1 and atrogin-1 in rat skeletal muscle 20,24,25 $^{2}$ through the $\mathrm{NF}^{20} \mathrm{~B}^{20}$ and $\mathrm{MAPK}^{25}$ pathways, respectively.

Although inflammatory joint conditions are common and clinical studies have shown morphological and functional alterations in the muscles related to injured joints ${ }^{12,26,27}$, the molecular mechanism related to the muscle adaptation to joint inflammation has not been studied to date. We hypothesized that joint inflammation induces molecular and structural changes in the soleus muscle related to the inflamed joint, i.e. the expression and content of pro-inflammatory mediators that regulate the expression of genes involved in the control of muscle mass will increase, inducing muscle fiber atrophy. These changes will start in the acute phase of inflammation (at 2 days) and will be maintained throughout the chronic phase of inflammation ( 7 and 15 days). In addition, the results will be due to joint inflammation itself and not only to disuse of the hindlimb or the capsular distension due to effusion. Thus, the aim of this study was to evaluate the effects of tibiotarsal joint inflammation induced by carrageenan on the genes related to atrophy (atrogin-1 and MuRF1), differentiation and growth (MyoD), mass regulation (myostatin), and pro-inflammatory factors (p38MAPK, NFkB and TNF-alpha) and on the expression of the TNF-alpha protein in the rat soleus muscle. Possible changes in the muscle fiber CSA were also assessed.

\section{Method}

\section{Animal care and experimental groups}

This study was conducted in accordance with the National Guide for Care and Use of Laboratory Animals and with the approval of the Ethics Committee (no. 049/07) of Universidade Federal de São Carlos, SP, Brazil. Sixty Wistar rats $(310 \pm 12$ g) were used. The animals were housed in plastic cages in a room with controlled environmental conditions and had free access to water and standard food. The animals were randomly divided into three experimental groups (2, 7, and 15 days) and then randomly assigned to four groups (Control, Sham, Inflammation, and Immobilization) within each experimental period (Figure 1). The Sham group was proposed to identify any influence of joint effusion on muscle adaptation. The Immobilization group was used as a parameter to investigate if the results in the Inflammation group were caused by the inflammatory process per se or if the hindlimb movement restriction, due to pain, could exert some influence on the results. The animals were anesthetized with an intraperitoneal injection of xylazine $(12 \mathrm{mg} / \mathrm{kg})$ and ketamine $(95 \mathrm{mg} / \mathrm{kg})$ for all experimental procedures. The animals from the Inflammation and Sham groups were injected with l-carrageenan or saline solution, respectively, into the right tibiotarsal joint. Joint inflammation was induced with $0.03 \mathrm{ml}$ of 3\% 1-carrageenan (Sigma Chemical Company, St. Louis, USA) dissolved 


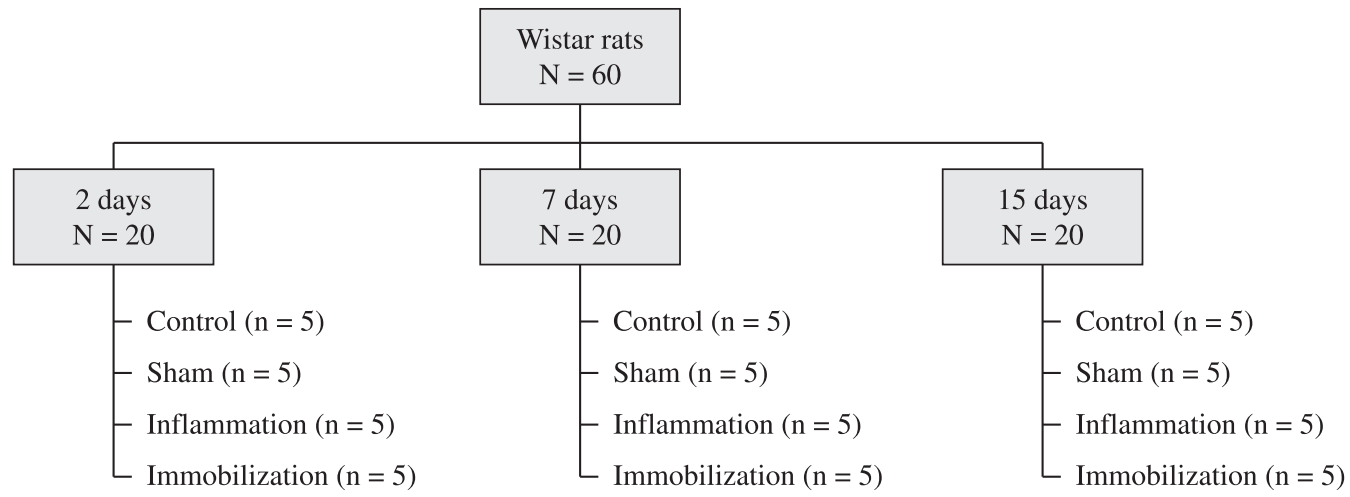

Figure 1. Distribution of experimental groups used in the study.

in saline solution $(0.9 \% \mathrm{NaCl})$, as described by Wang et al. ${ }^{28}$ and Omote et al. ${ }^{29}$ In the immobilization group the right tibiotarsal was immobilized according to Coutinho et al. ${ }^{30}$ in a neutral position.

At the end of the experimental period (2, 7, and 15 days), the right soleus muscle was dissected and removed. The muscle was weighed and then divided in half at the middle belly. The proximal fragment was divided in half again, immediately frozen in liquid nitrogen and stored at $-80^{\circ} \mathrm{C}$ (Forma Scientific, Marietta, $\mathrm{OH}$ ); the fragments were used for the mRNA and protein expression analyses. Distal fragments of the muscle were frozen in isopentane in liquid nitrogen, stored at $-86^{\circ} \mathrm{C}$ and used for histological, immunofluorescence, and muscle fiber CSA measurements. After muscle removal, the animals were euthanized with an overdose of anesthesia.

\section{Muscle fiber CSA analysis}

Histological cross-sections $(10 \mu \mathrm{m})$ from the middle belly of each right soleus muscle were obtained using a cryostat (Micron HE 505, Jena, Germany), stained with Toluidine Blue/1\% Borax (TB), and analyzed by light microscopy (Axiolab, Carl Zeiss, Jena, Germany) to evaluate the muscle fiber CSA. Images were obtained with a light microscope equipped with a digital camera (Sony DSCs75, Tokyo, Japan). The CSAs of 100 randomly chosen fibers were measured using Axiovision 3.0.6 SP4 software (Carl Zeiss, Jena, Germany). All of the measurements were made by a blinded evaluator.

\section{RNA isolation and analysis}

A frozen fragment from each right soleus muscle was homogenized, and the total RNA was isolated using Trizol reagent (Invitrogen, Carlsbad, CA) according to the manufacturer's recommendations The extracted RNA was dissolved in Tris-HCl and ethylene-diamine-tetracetic acid (EDTA) $\mathrm{pH}$ 7.6, and its concentration was quantified spectrophotometrically. RNA purity was assessed by determining the ratio of the absorbance at $260 \mathrm{~nm}$ to $280 \mathrm{~nm}$ (ratios were between 1.8 and 2.0). The integrity of the RNA was confirmed by electrophoretic analysis of the $18 \mathrm{~S}$ and $28 \mathrm{~S}$ ribosomal RNAs, which were stained with ethidium bromide (Invitrogen, Carlsbad, CA).

\section{Reverse transcription}

One microgram of total RNA was used to synthesize cDNA. The reverse transcription reaction (RT) mixture contained 5x first-strand buffer, a dNTP (Promega, Madison, WI) mixture with $0.2 \mathrm{mmol} \cdot \mathrm{L}^{-1}$ each of dATP, dCTP, dGTP, and $0.1 \mathrm{~mol} \cdot \mathrm{L}^{-1}$ of dTTP, $1 \mu \mathrm{l}$ of oligo (dT) primer (Invitrogen, Carlsbad, CA) and $200 \mathrm{U}$ of M-MLV RT enzyme (Promega, Madison, WI). The reverse transcription reaction was incubated at $70^{\circ} \mathrm{C}$ for $10 \mathrm{~min}, 42^{\circ} \mathrm{C}$ for $60 \mathrm{~min}$, and $95^{\circ} \mathrm{C}$ for $10 \mathrm{~min}$ before quick chilling on ice.

\section{Analyses by real-time polymerase chain reactions}

RNA transcript levels for the different experimental and control muscles were analyzed simultaneously, and the reactions were performed twice with a Lightcycler (Rotor Gene 3000, Cobertt Research, San Francisco, USA) using SYBR green fluorescent dye detection (Applied Biosystems, Foster City, CA) and $180 \mathrm{nM}$ of each primer in a final volume of $50 \mu \mathrm{l}$. The cycling conditions for the target genes have been previously described ${ }^{31-33}$. Data were analyzed using the comparative cycle threshold $(\mathrm{Ct})$ method described by the manufacturer; GAPDH was 


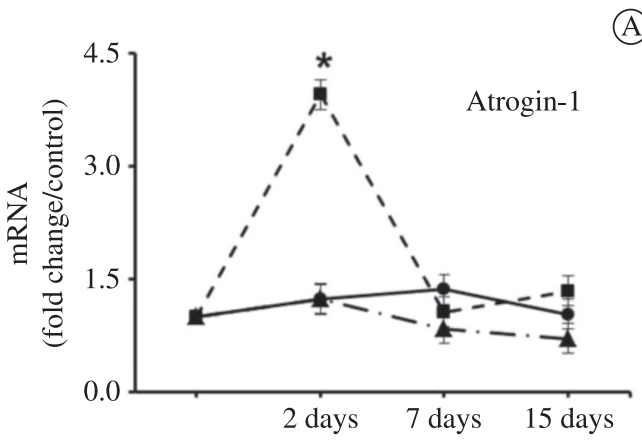

(A)
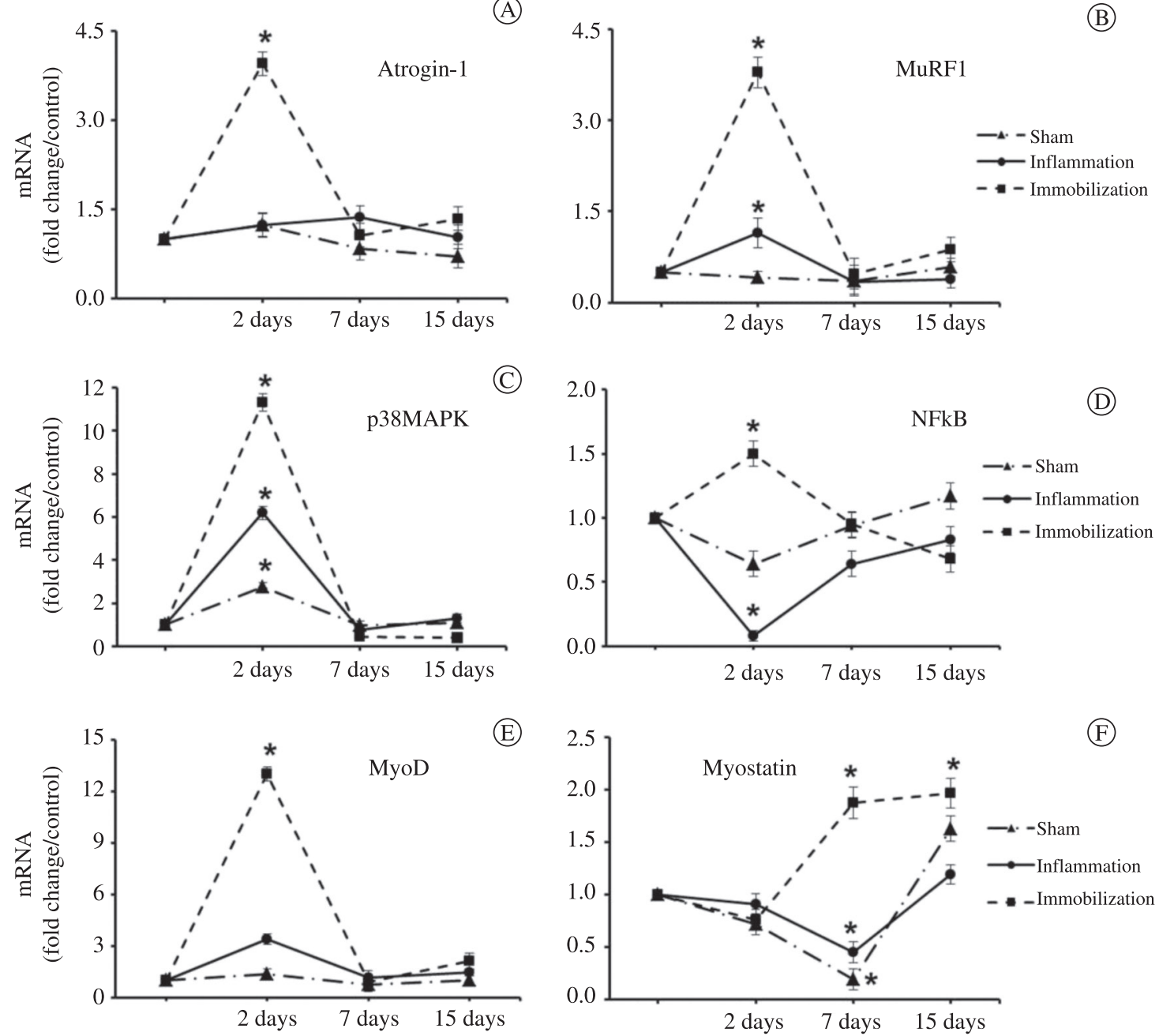

Figure 2. Gene expression of atrogin-1 (A), MuRF1 (B), p38MAPK (C), NFkB (D), MyoD (E), and myostatin (F) in the soleus muscle of the sham, inflammation, and immobilization groups at 2,7 , and 15 days. *p $<0.05$ vs. control. Data are expressed as mean \pm SD.

the control gene. In Figure 2, the control levels are arbitrarily set to 1 . Negative controls contained RNA but no M-MLV RT, ensuring that the PCR product was not a result of amplified genomic DNA. A blank control that only contained water, primers, and SYBR green was also performed.

\section{Oligonucleotide primers}

Oligonucleotide primers were designed for GAPDH (GenBank, AF106860), atrogin-1 (GenBank AF441120), and myostatin (GenBank AF019624) using the Primer Express Software 2.0 (Applied Biosystems, Foster City, California). Primers have been previously described for MuRF1, ${ }^{34}$ MyoD ${ }^{17} \mathrm{p}^{38 \mathrm{MAPK}^{25} \text {, and NFkB }}{ }^{35}$. The primers used for the amplification of products were as follows:
GADPH Fw-GATGCTGGTGCTGAGTATGTCG, Rv-GTGGTGCAGGATGCATTGCTGA;

atrogin-1 Fw-TACTAAGGAGCGCCATGGATACT, Rv-GTTGAATCTTCTGGATCCAGGAT;

M uRF 1 Fw-T G T C T G G A G G T C G T T T C C G, Rv-ATGCCGGTCCATGATCACTT;

myostatin Fw-CTACCACGGAAACAATCATTACCA, Rv-AGCAACATTTGGGCTTTCCAT;

My о D Fw-GGAGACATC C TCAAGCGATGC, Rv-AGCACCTGGTAAATCGGATTG;

p38MAPK Fw-AGCTGAACAAGACAATCTGGGA, Rv-CATAGGCGCCA-GAGCCC;

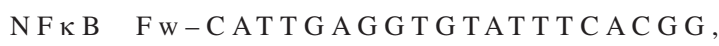
Rv-GGCAAGTGGCCATTGTGTTC. 


\section{Western blot analysis}

Protein was extracted from muscles in a lysis buffer $(50 \mathrm{mM}$ Tris- $\mathrm{HCl} \mathrm{pH} 7.4,1 \% \mathrm{w} / \mathrm{v}$ Triton $\mathrm{X}-100,0.25 \%$ sodium deoxycholate, $150 \mathrm{mM}$ sodium chloride, $1 \mathrm{mM}$ phenyl methylsulfonyl fluoride, $1 \mu \mathrm{g} / \mathrm{ml}$ aprotinin, $1 \mu \mathrm{g} / \mathrm{ml}$ leupeptin, $1 \mathrm{mM}$ sodium orthovanadate, and $1 \mathrm{mM}$ sodium fluoride). Equal amounts of protein $(80 \mu \mathrm{g})$ from each muscle lysate were separated by sodium dodecylsulfate-polyacrylamide gel electrophoresis (SDS-PAGE) and transferred to a nitrocellulose membrane. Membranes were stained with Ponceau $\mathrm{S}$ to confirm protein transfer and then rinsed with TBST. Membranes were blotted with antibodies against TNF-alpha (1:300, Santa Cruz Biotechnology, sc-80383). After incubation, membranes were rinsed in TBST and incubated with a secondary antibody against goat immunoglobulin G (KPL, 14-13-06; $1: 2000,0.1 \%$ nonfat dried milk in TBST). Detection of the labeled protein was done using the enhanced chemiluminescence system (ECL, Amersham, UK).

\section{Statistical analysis}

Shapiro-Wilk's and Levene's tests were applied to evaluate the normality and homogeneity, respectively, of the results. One-way analysis of variance (ANOVA), followed by Tukey's test, was performed to compare the groups. Non-parametric data were analyzed using a Kruskal-Wallis test followed by a Newman-Keuls test. For all tests, $\mathrm{p}<0.05$ was considered statistically significant.

\section{Results}

\section{Muscle fiber CSA}

The muscle fiber CSA decreased in the immobilization group at 2, 7, and 15 days compared with the control $(\mathrm{p}<0.05$; Table 1$)$. The inflammation group displayed muscle fiber CSA reduction at 7 and 15 days compared with the control $(\mathrm{p}<0.01)$. No changes were detected in the sham group (Table 1).

\section{Gene expression}

Atrogin-1. At 2 days, atrogin-1 increased (3.6fold) only in the immobilization group compared with the control $(\mathrm{p}<0.05)$. At 7 and 15 days, this gene was expressed at basal levels in all groups (Figure 2A).

MuRF1. MuRF1 mRNA levels increased in the inflammation (2.3-fold) and immobilization groups (7.6-fold) at 2 days compared with the control $(\mathrm{p}<0.001)$. At 7 and 15 days, this overexpression returned to basal levels in both groups (Figure 2B).

p38MAPK. p38MAPK was overexpressed at 2 days in the sham (2.7-fold), inflammation (6.2-fold), and immobilization (11.3-fold) groups compared with the control $(\mathrm{p}<0.05$; Figure $2 \mathrm{C})$. After 7 and 15 days, the gene expression returned to basal levels in all groups (Figure 2C).

$\mathbf{N F} \kappa \mathbf{B}$. At 2 days, this gene showed decreased expression in the inflammation group (0.08-fold) and increased expression in the immobilization group (1.5-fold) compared with the control $(\mathrm{p}<0.05)$. At 7 and 15 days, expression was at basal levels in all groups (Figure 2D).

MyoD. MyoD was strongly upregulated only in the immobilization group (15-fold) at 2 days; the expression returned to basal levels at 7 and 15 days (Figure 2E).

Myostatin. There was no change in myostatin expression levels in any group at 2 days. At 7 days, there was decreased myostatin expression in the inflammation (0.4-fold) and sham (0.2-fold) groups, and at 15 days, the expression returned to basal levels in both groups (Figure 2F). In the immobilization group, myostatin expression increased (1.9-fold) at 7 days and 15 days (1.9-fold) compared with the control $(\mathrm{p}<0.05$; Figure $2 \mathrm{~F})$.

Table 1. Muscle fiber cross-sectional area $\left(\mu \mathrm{m}^{2}\right)$ in the soleus muscle at 2, 7, and 15 days.

\begin{tabular}{lccc}
\hline \multicolumn{1}{c}{ Group } & $\mathbf{2}$ days $(\mathbf{n = 2 0})$ & $\mathbf{7}$ days $(\mathbf{n}=\mathbf{2 0})$ & $\mathbf{1 5}$ days $(\mathbf{n = 2 0})$ \\
Control $(\mathrm{n}=5)$ & $1925 \pm 94.5$ & $2063 \pm 140.3$ & $1990 \pm 350.2$ \\
Sham $(\mathrm{n}=5)$ & $1878 \pm 270.8$ & $1863 \pm 373.3$ & $1652 \pm 130.7$ \\
Inflammation $(\mathrm{n}=5)$ & $1974 \pm 320.3$ & $904 \pm 162.6^{*}$ & $1362 \pm 250.5^{*}$ \\
Immobilization $(\mathrm{n}=5)$ & $1358 \pm 110.1^{*}$ & $1087 \pm 150.6^{*}$ & $1323 \pm 280.1^{*}$ \\
\hline
\end{tabular}

Data are expressed as mean \pm SD. $* \mathrm{p}<0.05$ vs. control. 


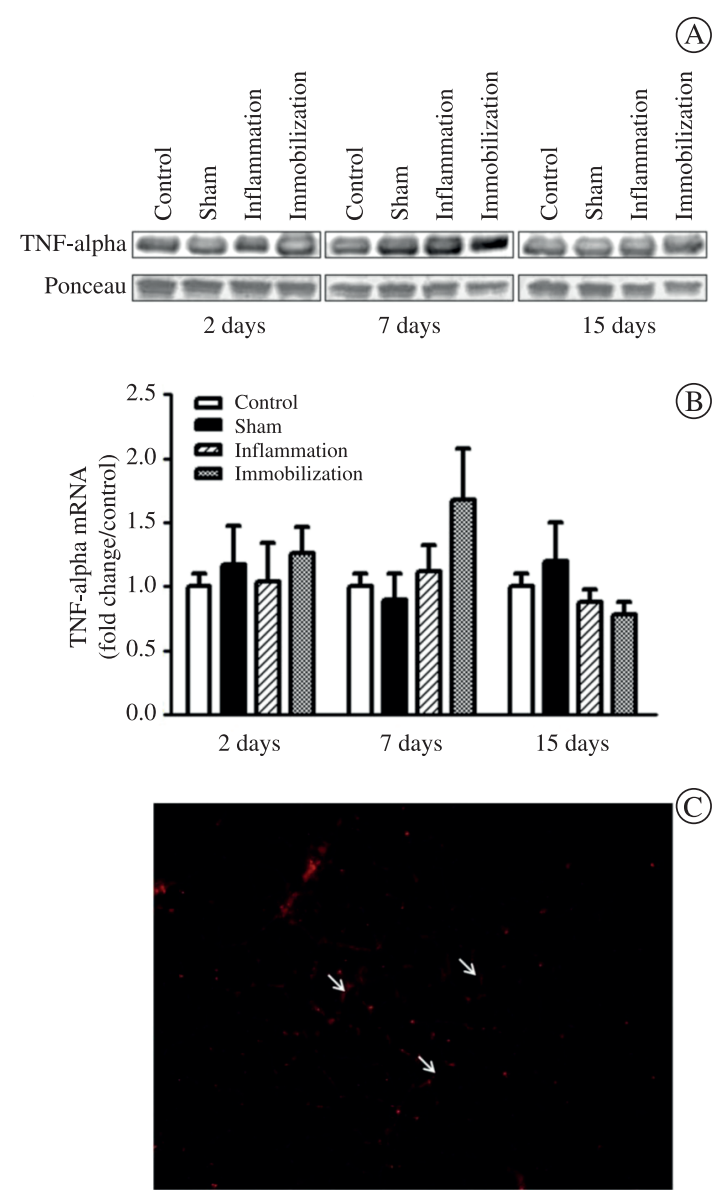

Figure 3. (A) The top row shows the representative blots of TNFalpha in the control, sham, inflammation, and immobilization groups at 2, 7, and 15 days. The lower row shows the respective bands stained with Ponceau S. (B) Gene expression of TNFalpha in the control, sham, inflammation, and immobilization groups at 2, 7, and 15 days. Data are presented as mean $\pm \mathrm{SD}$. (C) Immunofluorescence image of TNF-alpha for the control, sham, inflammation, and immobilization groups at 2, 7, and 15 days. The white arrows indicate endomysium immunoreactivity to TNF-alpha that was observed in all experimental groups.

\section{TNF-alpha}

Protein and gene expression of TNF-alpha was not altered in any group at any time point (Figure $3 \mathrm{~A}$ and $3 \mathrm{~B}$ ), which was confirmed by the qualitative analyses of immunofluorescence staining (Figure 3C).

\section{Discussion}

\section{Muscle response to joint inflammation}

Our study provides new information regarding the adaptation of slow-twitch muscle in response to joint inflammation. It has already been demonstrated that intra-articular injection of carrageenan triggers an acute inflammatory process during the first few days. Then, this response is converted to a macrophagedominated chronic inflammation response by the first week, and it lasts through the 8 th week $^{6}$. Thus, in the present study, day 2 after carrageenan injection was considered the acute phase of inflammation, and both day 7 and 15 represented the chronic phase.

At 2 days, we observed that the joint inflammation altered the expression of MuRF1, an atrogene involved in the protein degradation pathway. However, this change was not sufficient to induce muscle atrophy. Probably the initial up-regulation of MuRF1 is related to the late onset muscle fiber atrophy observed on days 7 and 15 in the inflamed groups. Conversely, atrogin-1 on soleus muscle did not change its expression due to inflammation joint. Furthermore, the present results did not corroborate previous studies that showed a direct relationship between p38MAPK and atrogin- $1^{24}$, once the increased levels of $\mathrm{p} 38 \mathrm{MAPK}$ observed on day 2 were not reflected into high levels of atrogin-1.

A previous study by our group showed a significant up-regulation of atrogin-1, MuRF1, and myostatin on fast-twitch muscle (tibialis anterior) at 2 days after carrageenan injection ${ }^{7}$. This pattern was quite different from that observed in the present study and suggests distinct molecular programs for muscle adaptation to inflammation in fast- and slow-twitch muscles.

In our study, the muscle fiber CSA was reduced during chronic joint inflammation (at 7 and 15 days), however the expression of two important genes that are involved in muscle-specific ubiquitination, atrogin- 1 and MuRF1, was not increased. The atrophy detected in the soleus muscle at 7 and 15 days in the inflammation group suggests that this response was regulated not only by atrogin-1 and MuRF1, but also through other mediators. Probably, pathways related to translational regulation and the apoptotic process could be involved in the soleus muscle adaptation. According to Oishi et al. ${ }^{36}$, the apoptotic response could be a key factor that induces atrophy in the soleus muscle.

The same pattern was observed for the expression of NFk $\beta$, p38MAPK, and TNF-alpha, which are other important mediators of muscle protein degradation ${ }^{20,25,37}$. In addition, neither TNF-alpha mRNA nor its protein content was altered in the 
inflammation group. TNF-alpha is a cytokine associated with muscle atrophy; it increases muscle proteolysis and inhibits skeletal muscle protein synthesis by altering the initiation of translation ${ }^{22,38}$. Therefore, our results indicate that sensitive markers of muscle atrophy analyzed in our study, at these time points, were not involved in the atrophy of the soleus muscle due to joint inflammation. Probably other proinflammatory factors such as IL-1 $\beta$, IL-6, TGF- $\beta$ and TWEAK could be involved in the atrophic process. Furthermore, calpains, apoptosis, and autophagic pathways should also be investigated in slow-twitch muscles in future studies of joint inflammation.

In our study, myostatin expression and the muscle fiber CSA at 7 days were reduced in the inflammation group. In humans, a reduction in myostatin expression associated with muscle hypertrophy has been observed ${ }^{39}$. Caron et al. ${ }^{40}$ identified that skeletal muscle atrophy could be associated with the up-regulation of myostatin. Interestingly, the gene expression of NFkB at 2 days in the inflammation group was also unexpectedly reduced in our study. A previous study also reported a reduction in this pro-inflammatory factor in muscle disuse due to immobilization ${ }^{21}$, but the significance of this reduction has not been clarified in the literature to date. Regarding these unexpected findings involving myostatin and NFkB expressions, a previous study showed a relationship between myostatin, TNF- $\alpha$, and $\mathrm{NFkB}^{41}$. The authors described that both TNF- $\alpha$ and NFkB can upregulate myostatin via reactive oxygen species (ROS) induction in muscle cells, providing evidence of the catabolic signaling pathway during muscle atrophy ${ }^{41}$. Conversely, as no difference in the amount of TNF- $\alpha$ protein was observed in the present study, the reduction in NFkB expression at 2 days probably downregulated the expression of myostatin at 7 days. This temporal pattern observed in these two genes could be related to the time point observed in the present study. The peak expression of MuRF-1 observed at 2 days could be preceded by an increase in myostatin and NFkB expressions. Furthermore, the downregulation of both myostatin and $\mathrm{NFkB}$ are probably related to normal levels of atrogene expression at 7 and 15 days. Together, these results call for new studies to investigate these factors immediately after inflammation, e.g. a few hours after joint injury, to support or refute these hypotheses.
These results have some limitations, however they also provide new insights into clinical practice. Regarding limitations, in order to clarify the mechanisms involved in the muscle atrophy observed at 7 and 15 days, it is necessary to investigate other molecular pathways related to inflammation, protein synthesis, apoptosis, and other pathways related to atrophy, such as calpains and the autophagic system. Regarding clinical practice, the results showed that, during joint inflammation, slow-twitch muscles responded differently than fast-twitch muscles ${ }^{7}$, therefore the rehabilitation team should focus on controlling the acute joint inflammation to prevent deleterious effects due to chronic inflammation on muscles functionally related to the affected joint. Therapeutic resources commonly prescribed by physical therapists, such as cryotherapy, lowlevel laser therapy, ultrasound, and electrical stimulation, should be recommended to control joint inflammation, however more investigation about their effects is also necessary. On the other hand, it seems that slow-twitch muscles are more sensitive to atrophy at chronic phases of joint inflammation compared to fast-twitch muscles ${ }^{7}$. Special attention should be given to these affected muscles, for example, through protocols of resistance training for recovery.

\section{Muscle response to immobilization}

The immobilization group was used as a parameter to investigate if the results obtained in the inflammation group were caused by an inflammatory process or if the hindlimb movement restriction, due to the pain, could exert some influence on the results. As observed in Figure 2, gene expression in the inflammation group was very distinct from that found in the immobilization group, thus confirming our initial hypothesis that muscle adaptation occurred due to inflammation and not to immobilization. The first 2 days of joint inflammation correspond to the period when limb restriction was more evident due to pain, although molecular and morphological findings were very distinct from the immobilization group, confirming that inflammation itself was the most important factor in these changes to the soleus muscle.

The immobilization group showed a classical pattern of atrophy. At 2 days, the muscle fiber CSA reduction was detected in combination with the elevated gene expression levels of atrogin-1, MuRF1, 
p38MAPK, and NFkB. This response confirms the pivotal role of the ubiquitin-proteasome pathway and of protein degradation in the early stage of atrophy in muscles that have been subjected to immobilization ${ }^{13,14,16}$. The up-regulation of those genes could be influenced by the elevated oxidative stress following immobilization ${ }^{40,42}$. The upregulation of MyoD at 2 days in the immobilization group could be related to a possible change from type I to type II fibers, as reported during the atrophic process in slow-twitch muscles ${ }^{25,43}$.

At 7 and 15 days after immobilization, there was no increased expression of those genes related to the proteolytic pathway, although the muscle fiber CSA remained reduced (Table 1). According to Calura et al. $^{44}$, protein degradation is an early response to the stimulus that induces atrophy. This response is subsequently masked and likely occurs through the biological process of muscle adaptation to atrophy. In our study, important genes related to the protein degradation were activated prior to day 7; and at 7 and 15 days of immobilization, other molecular mediators could be responsible for the muscle atrophy detected.

A potential mechanism involved in the response described in the immobilization group at 7 and 15 days could be a decrease in protein synthesis. Previous studies have shown that the rates of protein synthesis in the soleus muscle decrease after unloading and denervation ${ }^{45}$. These results differ from those observed in the fast-twitch muscle, in which denervation-induced atrophy is characterized by an increase in protein synthesis; this implies an even greater contribution of protein degradation to type II muscle fiber atrophy ${ }^{46,47}$. Future studies to analyze the regulation of protein synthesis during immobilization are necessary.

Myostatin expression was up-regulated at 7 and 15 days in the immobilization group. It has been observed that, in the presence of an atrophic stimulus such as immobilization, an increase in myostatin expression is accompanied by a decrease in MyoD expression $^{48}$. Thus, our results suggest that the increased myostatin expression could induce muscle atrophy and elicit the down-regulation of musclespecific genes, such as MyoD.

\section{Muscle response to joint effusion}

The injection of any substance into the joint space can generate joint effusion. It has already been described in the literature that capsular distension changes the proprioceptive outputs to muscles functionally related to that joint. Thus, we believe that capsular distension caused by the volume of carrageenan injected could be a source of bias. The results of the inflammation group were quite different from those observed in the sham group, and this supports the premise that the results in the inflammation group were due to the inflammatory process itself. The changes in gene expression in the sham group indicate that joint effusion is able to generate molecular alterations in the muscle that are functionally related to the injured joint, although without any muscle fiber atrophy.

A mechanism by which this muscle response could be mediated is the arthrogenic muscle response (AMR). AMR is generated by elevated tension inside the joint capsule, which increases or decreases the extent of the H-reflex in muscles that are functionally related to the affected joint; this process can occur even without an associated joint injury ${ }^{49}$. H-reflex inhibition in joint effusion could result in the inhibition of the alpha motoneuron pool in the agonist muscle, and alpha motoneuron facilitation has been observed in the antagonist muscle group ${ }^{50}$. Thus, in our study, the tibiotarsal joint effusion could have caused activation in the soleus motor units and, in this manner, stimulated the detected gene expression. However, future studies should investigate this hypothesis using EMG and H-reflex measurements.

This study had some limitations. For example, other molecular pathways involved with muscle atrophy such as calpains, autophagic system, and inflammatory cytokines (IL-1 $\beta$, IL-6 and IL-8), hypertrophy (IGF-1/IPI3/Akt), and apoptosis should be assessed in future studies to elucidate the mechanisms involved in the muscle response observed in the soleus muscle. Furthermore, electrophysiological studies could contribute to evaluate the changes in the pattern of motor unit recruitment in muscles functionally related to the affected joint.

In conclusion, our study showed that acute joint inflammation induced the expression of some genes related to the proteolytic pathway without reducing the muscle fiber CSA. Conversely, chronic joint inflammation generated muscle atrophy without up-regulating the genes involved in the proteolytic pathway, such as atrogin-1, MuRF1, NFאB, 
p38MAPK, and TNF-alpha. This pattern was similar to that observed at 7 and 15 days of immobilization. This result shows that, in the soleus, muscle atrophy due to joint inflammation and immobilization after 7 days could be mediated by ubiquitin ligases different from the atrogin- 1 and MuRF1, or could be mediated by other molecular pathways not analyzed in our study. Although this study was conducted with rats, it has clinical relevance and indicates that muscle adaptation can vary according to the stage of the inflammatory process. It also suggests the importance of controlling the acute joint inflammatory response through therapeutic interventions including skeletal muscle activation to prevent the noxious effects caused by chronic joint inflammation on the muscle that is functionally related to the inflamed joint.

\section{References}

1. Serhan C, Ward P, Gilroy D. Fundamentals of Inflammation. Cambridge: Cambridge University Press; 2010.

2. Sharma P, Maffulli N. Tendon Injury and Tendinopathy: Healing and Repair. J Bone Joint Surg Am. 2005;87:187202. PMid:15634833. http://dx.doi.org/10.2106/ JBJS.D.01850

3. Bastian O, Pillay J, Alblas J, Leenen L, Koenderman L. Systemic inflammation and fracture healing. J Leukoc Biol. 2010;2:34-40.

4. Sandoval MC, Ramírez C, Camargo DM, Salvini TF. Effect of high-voltage pulsed current plus conventional treatment on acute ankle sprain. Rev Bras Fisioter. 2010;14:193-200. PMid:20730362.

5. Loram LC, Fuller A, Fick LG, Cartmell T, Poole S, Mitchell D. Cytokines profiles during carrageenan-induced inflammatory hyperalgesia in rat muscle and hind paw. J Pain. 2007;8:127-136. PMid:16949880. http://dx.doi. org/10.1016/j.jpain.2006.06.010

6. Radhakrishnana R, Moorec SA, Slukaa KA. Unilateral carrageenan injection into muscle or joint induces chronic bilateral hyperalgesia in rats. Pain. 2003;104:566-577. http://dx.doi.org/10.1016/S0304-3959(03)00114-3

7. Ramírez C, Russo TL, Sandoval MC, Dentillo AA, Couto MAS, Durigan JLQ. Joint inflammation aters gene and protein expression and leads to atrophy in the tibialis anterior muscle in rats. Am J Phys Med Rehabil. 2011;11:930-939.

8. Guillot C, Steinberg JG, Delliaux S, Kipson N, Jammes Y, Badier M. Physiological, histological and biochemical properties of rat skeletal muscles in response to hindlimb suspension. J Electromyogr Kines. 2006;2:276-283.

9. Lieber R. Skeletal muscle adaptation to decreased use. In: Lieber R. Skeletal muscle structural, function \& plasticity. Philadelphia: Lippincott Williams \& Wilkins; 2002.
10. Gür H, Çakin N. Muscle mass, isokinetic torque, and functional capacity in women with osteoarthritis of the knee. Arch Phys Med Rehabil. 2003;84:1534-1541. http:// dx.doi.org/10.1016/S0003-9993(03)00288-0

11. Hurley MV. The effects of joint damage on muscle function, propioception and rehabilitation. Man Ther. 1997;2:11-17. PMid:11440520. http://dx.doi. org/10.1054/math.1997.0281

12. Suetta C, Aagaard P, Magnusson S, Andersen L, Sipilä S, Rosted A, et al. Muscle size, neuromuscular activation, and rapid force characteristics in elderly men and women: effects of unilateral long-term disuse due to hip-osteoarthritis. J Appl Physiol. 2007;102:942948. PMid:17122381. http://dx.doi.org/10.1152/ japplphysiol.00067.2006

13. Bodine SC, Latres E, Baumhueter S, Lai VK, Nunez L, Clarke BA, et al. Identification of ubiquitin ligases required for skeletal muscle atrophy. Science. 2001;294:1704-1707. PMid:11679633. http://dx.doi.org/10.1126/ science. 1065874

14. Gomes MD, Lecker SH, Jagoe RT, Navon A, Goldberg AL. Atrogin-1, a muscle-specific F-box protein highly expressed during muscle atrophy. Proc Natl Acad Sci USA. 2001;98:14440-14445. PMid:11717410 PMCid:64700. http://dx.doi.org/10.1073/pnas.251541198

15. Lecker SH, Solomon V, Mitch WE, Goldberg AL Muscle protein breakdown and the critical role of the ubiquitinproteasome pathway in normal and disease state. J Nutr. 1999;129:227S-237S. PMid:9915905.

16. Sacheck JM, Hyatt JP, Raffaello A, Jagoe RT, Roy $\mathrm{RR}$, Edgerton RV, et al. Rapid disuse and denervation atrophy involve transcriptional changes similar to those of muscle wasting during systemic diseases. FASEB J. 2007;21:140-155. PMid:17116744. http://dx.doi. org/10.1096/fj.06-6604com

17. Ishido M, Kami K, Masuhara M. In vivo expression patterns of MyoD, p21 and RB proteins in myonuclei and satellite cells of denervated rat skeletal muscle. Am J Physiol Cell Physiol. 2004;287:484-493. PMid:15084472. http://dx.doi.org/10.1152/ajpcell.00080.2004

18. Walters EH, Stickland NC, Loughna PT. The expression of the myogenic regulatory factors in denervated and normal muscles of different phenotypes. J Muscle Res Cell Motil. 2000;21:647-653. PMid:11227791. http:// dx.doi.org/10.1023/A:1005683825960

19. Wojcik S, Nogalska A, Engel WK, Askanas V. Myostatin and its precursor protein are increased in the skeletal muscle of patients with Type-II muscle fiber atrophy. Folia Morphol. 2008;67:1-7.

20. Cai D, Frantz JD, Tawa NE, Melendez PA, Lidov $\mathrm{H}$, Hasselgren GW, et al. IKKbeta/NF-kappaB activation causes severe muscle wasting in mice. Cell. 2004;119:285-298. PMid:15479644. http://dx.doi. org/10.1016/j.cell.2004.09.027

21. LiH, MalhotraS, KumarA. Nuclear factor-kappa B signaling in skeletal muscle atrophy. J Mol Med. 2008;86:113-1126. 
PMid:18574572 PMCid:2597184. http://dx.doi. org/10.1007/s00109-008-0373-8

22. Land CH, Frost RA, Nairn AC, McLean DA, Vary TC. TNF- $\alpha$ impairs heart and skeletal muscle protein synthesis by altering translation initiation. Am J Physiol Endocrinol Metab. 2002;282:336-347.

23. Nishikori T, Irie K, Suganuma T, Ozaki M, Yoshioka T. Anti-inflammatory potency of FR167653, a p38 mitogenactivated kinase inhibitor, in mouse models of acute inflammation. Eur J Pharmacol. 2002;451:327-233. http:// dx.doi.org/10.1016/S0014-2999(02)02238-0

24. Glass DJ. Skeletal muscle hypertrophy and atrophy signaling pathways. Int J Biochem Cell Biol. 2005;37:1974-1984. PMid:16087388. http://dx.doi. org/10.1016/j.biocel.2005.04.018

25. Li YP, Chen Y, John J, Moylan J, Jin B, Reid M. TNF-alpha acts via $\mathrm{p} 38 \mathrm{MAPK}$ to stimulate expression of the ubiquitin ligase atrogin1/MAFbx in skeletal muscle. FASEB J. 2005;19:362-370. PMid:15746179 PMCid:3099533. http://dx.doi.org/10.1096/fj.04-2364com

26. LindehammarH,Londvall B. Muscleinvolvement in juvenile idiopathic arthritis. Rheumatology. 2004;43:1546-1554. PMid:15342926. http://dx.doi.org/10.1093/rheumatology/ keh381

27. Pap G, Machner A, Awiszus F. Strength and voluntary activation of the quadriceps femoris muscle at different severities of osteoarthitic knee joint damage. J Orthop Res. 2004;22:96-103. http://dx.doi.org/10.1016/ S0736-0266(03)00128-1

28. Wang Y, Huang C, Cao Y, Han Y. Repeated administration of low dose ketamine for the treatment of monoarthritic pain in the rat. Life Sci. 2000;67:261-267. http://dx.doi. org/10.1016/S0024-3205(00)00625-1

29. Omote K, Kawamata T, Nakayama Y, Yamamoto H, Kawamata M, Namiki A. Effects of a Novel Selective Agonist for Prostaglandin Receptor Subtype EP4 on Hyperalgesia and Inflammation in Monoarthritic Model. Anesthesiology. 2002;97:170-176. PMid:12131119. http:// dx.doi.org/10.1097/00000542-200207000-00024

30. Coutinhho AL, Gomes A, Franca CN, Salvini TF. A new model for the immobilization of rat hind limb. Braz J Biol Res. 2004;37:1473-1480.

31. Peviani S, Silveira A, Carreira R, Moriscot A, Salvini T. Short bouts of stretching increase myo-d, myostatin and atrogin-1 in rat soleus muscle. Muscle Nerve. 2007;35:363-370. PMid:17143883. http://dx.doi. org/10.1002/mus.20695

32. Russo T, Peviani S, Marques C, Gigo-Benato D, Salvini T. Electrical stimulation based on Chronaxie reduces atrogin-1 and Myod gene expressions in denervated rat muscle. Muscle Nerve. 2007;35:87-97. PMid:17034040. http://dx.doi.org/10.1002/mus.20668

33. Russo TL, Peviani SM, Duringan JL, Gigo-Benato, Delfino GB, Salvini TF. Stretching and electrical stimulation reduce the accumulation of $\mathrm{MyoD}$, myostatin and atrogin-1 in denervated rat skeletal muscle. J Muscle
Res Cell Motil. 2010;31:45-57. PMid:20191313. http:// dx.doi.org/10.1007/s10974-010-9203-Z

34. Granado M, Priego T, Martín A, Villanúa MA, LópezCalderon A. Ghrelin receptor agonist GHRP-2 prevents arthritis-induced increase in E3 ubiquitin-ligating enzymes MuRF1 and MAFbx gene expression in skeletal muscle. Am J Physiol Endocrinol Metab. 2005;289:1007-1014. PMid:16030067. http://dx.doi.org/10.1152/ ajpendo.00109.2005

35. Jokelainen K, Thomas P, Lindros K, Nanji A. Acetaldehyde inhibits NF-kappaB activation through IkappaBalpha preservation in rat Kupffer cells. Biochem Biophys Res Commun. 1998;253:834-836. PMid:9918814. http:// dx.doi.org/10.1006/bbrc.1998.9863

36. Oishi Y, Ogata T, Yamamoto K, Terada M, Ohira T, Ohira Y, et al. Cellular adaptations in soleus muscle during recovery after hindlimb unloading. Acta Physiol. 2008;192:381-395. PMid:17892520. http:// dx.doi.org/10.1111/j.1748-1716.2007.01747.x

37. Lang CH, Frost RA. Sepsis-induced supression of skeletal muscle translation initiation mediated by tumor necrosis factor $\alpha$. Metabolism. 2007;56:49-57. PMid:17161226. http://dx.doi.org/10.1016/j.metabol.2006.08.025

38. Glickman MH, Ciechanover A. The ubiquitin-preteasome proteolytic pathway:destruction for sake of construction. Physiol Rev. 2002;82:373-428. PMid:11917093.

39. Ryan AS, Ivey FM, Prior S, Li G, Hafer-Macko C. Skeletal muscle hypertrophy and muscle myostatin reduction after resistive Training in Stroke Survivors. Stroke. 2011;42:416420. PMid:21164115 PMCid:3026882. http://dx.doi. org/10.1161/STROKEAHA.110.602441

40. Caron AZ, Drouin G, Desrosiers J, Trensz F, Grenier G. A novel hindlimb immobilization procedure for studying skeletal muscle atrophy and recovery in mouse. J Appl Physiol. 2009;106:2049-59. PMid:19342435. http:// dx.doi.org/10.1152/japplphysiol.91505.2008

41. Sriram Sriram S, Subramanian S, Sathiakumar S, Venkatesh R, Salerno M, Craig D. McFarlane. Modulation of oxygen reactive species in skeletal muscle by myostatin is mediated through NFkB. Aging Cell. 2011;10:931-948. PMid:21771249. http://dx.doi. org/10.1111/j.1474-9726.2011.00734.x

42. Kondo H, Miura M, Itokawa Y. Oxidative stress in skeletal muscle atrophied by immobilization. Acta Physiol Scand. 1991;142:527-528. PMid:1950601. http://dx.doi. org/10.1111/j.1748-1716.1991.tb09191.x

43. Wheeler MT, Snyder EC, Patterson MN, Swoap SJ. An E-box within the MHC IIB gene is bound by MyoD and is regulated for gene expression in fast muscle. Am J Physiol Cell Physiol. 1999;276:1069-1078.

44. Calura E, Cagnin S, Raffaello A, LAveder P, Lanfranchi G, Romualdi C. Meta-analysis of expression signatures of muscle atrophy:gene interaction networks in early and late stages. BMC Genomics. 2008;9:630-650. PMid:19108710 PMCid:2642825. http://dx.doi. org/10.1186/1471-2164-9-630 
45. Thomason DB, Biggs RB, Booth FW. Protein metabolism and beta - myosin heavy mRNA in unweight soleus muscle. Am J Physiol Regulatory Integrative Comp Physiol. 1989;257:300-305.

46. Goldspink DF. The effect of denervation on protein turnover of rat skeletal muscle. Biochem J. 1976;71-80. PMid:942405 PMCid:1163718.

47. Hornberger TA, Hunter BR, Kandarian SC, Esser $\mathrm{K}$. Regulation of translation factors during hindlimb unloading and denervation of skeletal muscle in rats. Am J Physiol Cell Physiol. 2001;281:179-187.

48. Spiller MP, Kambadur R, Jeanplong F, Thomas M, Martin JK, Bass JJ, et al. The Myostatin gene is downstream target gene of basic helix-loop-helix transcription factor MyoD. Mol Cell Biol. 2002;22:7066-82. PMid:12242286 PMCid:139803. http://dx.doi. org/10.1128/MCB.22.20.7066-7082.2002

49. Palmieri RM, Ingersoll CD, Hoffman MA, Cordova ML, Porter DA, Edwards JE, et al. Arthrogenic muscle response to a simulated ankle joint effusion. Br J Sports Med. 2004;38:26-30. PMid:14751941 PMCid:1724745. http://dx.doi.org/10.1136/bjsm.2002.001677

50. Takada Y, Miyahara T, Tanaka T, Ohyama T, Nakamura Y. Modulation of H Reflex of Pretibial Muscles and Reciprocal Ia Inhibition of Soleus Muscle During Voluntary Teeth Clenching in Humans. J Neurophysiol. 2000;83:63-2070.

\section{Correspondence}

\section{Tania de Fátima Salvini}

Universidade Federal de São Carlos Physical Therapy Department Rod. Washington Luis, Km 235, CP 676 CEP 13565-905, São Carlos, SP, Brazil e-mail: tania@ufscar.br 